\title{
Product Line Potential Analysis
}

\author{
Claudia Fritsch and Ralf Hahn \\ Robert Bosch GmbH \\ Corporate Research and Development \\ P.O. Box 9403 50, D-60461 Frankfurt, Germany \\ \{Claudia.Fritsch|Ralf.Hahn\}@de.bosch.com
}

\begin{abstract}
A Product Line Potential Analysis enables us to make a quick decision as to whether the product line approach (PLA) is suitable for a given set of products and target market. The PLA framework offers no support for this as yet.

A Product Line Potential Analysis is executed in a half-day workshop. A structured interview based on a questionnaire examines products, software, markets, and customers. The answers are compared to a set of criteria for the applicability of the PLA. The analysis results primarily in one of these decisions: "yes" (the PLA is suitable for these products and markets), "no", or "investigation required". Up to now, our team has performed four Product Line Potential Analyses.

We present the list of criteria, a part of our questionnaire, and the workshop format. We discuss Product Line Potential Analysis in the light of related work and its limits and lessons learned, and we look at future work.
\end{abstract}

\section{Introduction}

\subsection{PLA Introduction at Bosch}

Robert Bosch manufactures and sells automotive products and industrial products, as well as consumer goods and building products worldwide. Many products are software-intensive systems with embedded software. Most of the software products form a product line.

Bosch started a product line approach (PLA) initiative in 1999 to increase software quality and development efficiency. The PLA should be introduced in those business units or product units where it makes sense.

Bosch business units are facing the question of whether to use the PLA. Before spending time and resources on a PLA, the business units must be certain that it is suitable for their products. To make this decision, the business unit needs to understand its product line potential, that is, the business opportunity of building software product lines in a systematic way.

The purpose of the Product Line Potential Analysis is to provide confidence in whether product line potential exists. 


\subsection{Product Line Potential}

Product line potential exists if a set of software-intensive systems sharing a common set of features that satisfy the specific needs of a particular market segment or mission can be developed from a common set of core assets.

This definition is derived from the definition of a software product line in Clements' and Northrop's book [2]: A software product line is a set of softwareintensive systems sharing a common set of features that satisfy the specific needs of a particular market segment or mission and that are developed from a common set of core assets in a prescribed way.

The difference is that product line potential only requires that systems can be developed from a common set of core assets. When considering that potential, the current practices are irrelevant. Instead, the question is if systematic product line development would be helpful.

Bosch's business units have developed embedded software for decades and have been following established processes and techniques. Over the years, the software has grown in complexity and size. Some business units now develop a variety of software products. How can a business unit find out if the PLA would be appropriate?

A Product Line Potential Analysis examines a business unit's product line potential through discussions with business unit managers who know their organization's business goals, products, and market requirements. This has to be done as quickly as possible: business unit managers have a tight schedule.

\section{Approach}

\subsection{Overview}

A Product Line Potential Analysis answers the following question: Would the PLA be suitable for a given set of products and target market? This question is too hard to answer as a whole, so we broke it down into a set of criteria relevant to the applicability of the PLA.

Figure 1 shows the development and application of the Product Line Potential Analysis (PLPA) method. Based on the definition of product line potential, product line suitability criteria are derived. The criteria, in turn, provide the basis for the questionnaire contents. In a Product Line Potential Analysis workshop, the answers are compared to the criteria. This comparison yields one of three decisions: "yes" (the PLA is suitable for these products and markets), "no", or "investigation required." In the written report, the answers are mapped to the definition of product line potential, providing the rationale. 


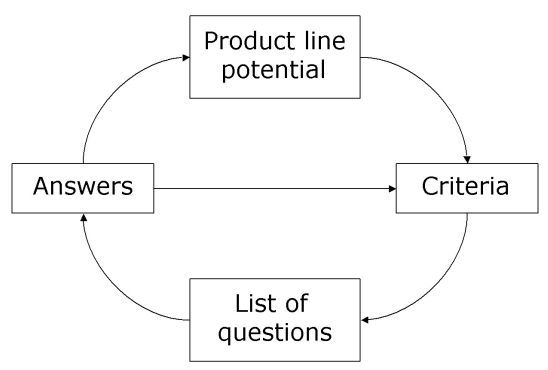

Fig. 1. PLPA cycle

\section{$2.2 \quad$ Criteria}

The following criteria are relevant to product line potential:

- Main criteria are essential for product line development and have to be fulfilled:

- The business unit develops more than one product.

- Products have common features.

- Products have common qualities.

- Inclusion criteria indicate that product lines already exist:

- The same part of software is used in more than one product.

- Supporting criteria apply if a business unit has problems that the PLA addresses:

- The business unit has quality problems.

- The business unit has complexity problems.

- The business unit expects increasingly differentiated products.

- Exclusion criteria rule out an economically advantageous product line:

- There is an immature, instable market for the products.

- There is technological change.

- The software is small; optimization will not be profitable.

- The software development effort is negligible. It would be better to focus on other improvements.

- New product development is too seldom.

- The business unit develops specific, commissioned custom products.

- Additional information is useful data that cannot be assigned to one of the preceding criteria:

- the competitive situation

Some criteria may appear to be trivial; for example, more than one product. But experience shows that this criterion should be checked.

Note: One fulfilled exclusion criteria does not imply that the PLA can not make sense. It only indicates that the PLA may not make sense.

From these criteria, questions that help to check the criteria have been derived. Table 1 shows a part of the questionnaire with 11 questions and their 
Table 1. A part of our questionnaire: questions and their correlation to criteria. Criteria and their qualifiers are given in short form for a better overview

\begin{tabular}{|c|c|c|c|}
\hline No. & Question & \multicolumn{2}{|c|}{ Criterion } \\
\hline \multicolumn{4}{|c|}{ Products } \\
\hline $\mathrm{P}_{1}$ & $\begin{array}{l}\text { Which products do you manufacture or sell at } \\
\text { the moment? }\end{array}$ & main & More than one product \\
\hline \multirow[t]{2}{*}{$\mathrm{P}_{2}$} & \multirow{2}{*}{$\begin{array}{l}\text { Which products do you develop at the } \\
\text { moment? When do they go into production? }\end{array}$} & excl & Immature, instable market \\
\hline & & excl & Technological change \\
\hline $\mathrm{P}_{3}$ & $\begin{array}{l}\text { How many products did you deliver during the } \\
\text { last } 12 \text { months? }\end{array}$ & excl & $\begin{array}{l}\text { New product development } \\
\text { is too seldom. }\end{array}$ \\
\hline $\mathrm{P}_{4}$ & $\begin{array}{l}\text { Which features do your products for one mar- } \\
\text { ket segment have in common? }\end{array}$ & main & Common features \\
\hline$\cdots$ & $\ldots$ & $\cdots$ & $\cdots$ \\
\hline \multicolumn{4}{|c|}{ Hardware and software } \\
\hline $\mathrm{S}_{1}$ & $\begin{array}{l}\text { How big is your software (lines of code, RAM- } \\
\text { /ROM usage, number of developers)? }\end{array}$ & excl & Software is small. \\
\hline $\mathrm{S}_{2}$ & $\begin{array}{l}\text { What is the proportionate cost of the software } \\
\text { in a product? }\end{array}$ & excl & $\begin{array}{l}\text { Software development effort } \\
\text { negligible }\end{array}$ \\
\hline $\mathrm{S}_{3}$ & $\begin{array}{l}\text { Do you use the same software parts in more } \\
\text { than one product? }\end{array}$ & incl & $\begin{array}{l}\text { Same software in more than } \\
\text { one product }\end{array}$ \\
\hline $\mathrm{S}_{4}$ & $\begin{array}{l}\text { Which differences between the products do you } \\
\text { implement in software? }\end{array}$ & incl & $\begin{array}{l}\text { Same software in more than } \\
\text { one product }\end{array}$ \\
\hline$\ldots$ & $\cdots$ & $\cdots$ & $\cdots$ \\
\hline \multicolumn{4}{|c|}{ Market } \\
\hline \multirow[t]{2}{*}{$\mathrm{M}_{1}$} & \multirow{2}{*}{$\begin{array}{l}\text { What is your market forecast for your } \\
\text { products? }\end{array}$} & excl & Immature, instable market \\
\hline & & supp & $\begin{array}{l}\text { Increasingly differentiated } \\
\text { products }\end{array}$ \\
\hline \multirow[t]{2}{*}{$\mathrm{M}_{2}$} & \multirow[t]{2}{*}{$\begin{array}{l}\text { Which market segments do you address? } \\
\text { In what way are they different? }\end{array}$} & excl & $\begin{array}{l}\text { New product development } \\
\text { is too seldom. }\end{array}$ \\
\hline & & main & Common qualities \\
\hline$\ldots$ & $\ldots$ & $\ldots$ & $\ldots$ \\
\hline \multicolumn{4}{|c|}{ Customers } \\
\hline $\mathrm{C}_{1}$ & $\begin{array}{l}\text { Do your customers commission you to develop } \\
\text { products and demand for software reuse? }\end{array}$ & incl & $\begin{array}{l}\text { Same software in more than } \\
\text { one product }\end{array}$ \\
\hline$\ldots$ & $\ldots$ & $\ldots$ & $\ldots$ \\
\hline
\end{tabular}


correlation to the criteria. Questions $\mathrm{P}_{\mathrm{i}}$ help to understand what kind of products the business unit builds. Questions $\mathrm{S}_{\mathrm{i}}$ look at the hardware and software. Questions $\mathrm{M}_{\mathrm{i}}$ about the market and $\mathrm{C}_{\mathrm{i}}$ about the customers' habits close the questionnaire.

The correlation between questions and criteria is not always evident. For example, question $\mathrm{P}_{2}$ ("Which products do you develop at the moment?") finds out whether there is an immature, instable market. If the products currently developed are different from those currently sold (question $\mathrm{P}_{1}$ ), this exclusion criterion is fulfilled.

\subsection{Questions}

While the criteria were derived from the definition of product line potential, the questions arose from experience. The questions were iterated several times, reconsidering successful product line development efforts, as well as attempts that failed.

Some questions ask what a business unit has done, such as $\mathrm{P}_{1}, \mathrm{P}_{3}$, and $\mathrm{P}_{4}$. In principle, products that a business unit plans to develop are more interesting - the PLA can have no influence on products already on sale. Nevertheless, questions about things that a business unit has done are especially attractive because they are facts - as opposed to plans, intentions, or forecasts.

Redundant questions ensure a consistent picture of products and markets. Usually, a product manager talks about the products in a different way than the head of development does. The criteria are therefore assessed from different perspectives. For example, two questions address the criterion same software in more than one product: $\mathrm{S}_{3}$ "Do you use the same software parts in more than one product?" and $\mathrm{C}_{1}$ "Do your customers [...] demand for software reuse?" Only two matching answers ensure that a criterion is covered.

The small set of keywords used in the questions helps to interpret information consistently. Ambiguous terms, such as "platform" or "component," have been avoided. Instead, more neutral terms are used, such as "products," "software," and "software parts."

The phrasing of the questions meets the principles of human communication: be open, positive, non-suggestive, and simple. The questions aim at informative answers: instead of "How many products do you manufacture or sell ...?" the better question is $\mathrm{P}_{1}$ "Which products do you manufacture or sell ...?" Some questions are rather indirect, because direct questions might force someone onto the defensive. For example, "Will you supply an immature and instable market?" would probably not yield a satisfying answer. Instead, the reply to question $\mathrm{M}_{1}$ "What is your market forecast for your products?" will allow the appropriate conclusions. Although some questions seem to miss the point, they have proven to serve their purpose very well. 
Table 2. Structure of a Product Line Potential Analysis workshop

1. Presentation of PLA and Product Line Potential Analysis method

2. Presentation of product portfolio and market

Break
3. Structured interview using the questionnaire
4. Review criteria and articulate the result

\subsection{Workshop Format}

The goal of the workshop is to

- inform the business unit personnel about potential benefits of the PLA

- inform the business unit personnel about what the PLA means in the context of the business unit's products

- learn about the business unit's goals, products, software, markets, and customers

- analyze products, software, markets, and customers to decide whether the PLA is suitable

The Product Line Potential Analysis addresses managers in business units or product units who have heard about the PLA but do not exactly know what it is. These managers call for information and want to know if the PLA is suitable for them. They are willing to spend some hours of their precious time, so they make an appointment for a Product Line Potential Analysis.

Preparation. Before the workshop, the client is asked to prepare presentations of his product portfolio and market. Usually, appropriate slides are already available.

The client gets the list of questions and is asked to bring one or two people who can answer them in the workshop. Usually, two or three business unit employees participate: a product manager, the head of the development department, and sometimes an architect.

Three of us team up for such a workshop: one is the lead who presents the PLA and Product Line Potential Analysis and asks the questions, one takes notes, and one acts as the observer and timekeeper.

Execution. The structure of a Product Line Potential Analysis workshop is shown in Table 2. During the presentation of the PLA and the Product Line Potential Analysis, the workshop lead informs the client about the PLA and sets the expectations for the Product Line Potential Analysis. After that, the product manager and the head of development present their markets and products.

After the presentations the team uses the break to cross out questions in the list that have already been answered. Questions whose discussion can be shortened are marked. 
Then, the structured interview starts, guided by the questionnaire. The business unit personnel answer the questions while the lead explains them and links their answers to the PLA. In this way, the business unit employees learn about the PLA in relation to their products and software. While the lead asks the questions, he or she ticks off the fulfilled criteria.

After the interview, the lead reviews the criteria and clarifies with the workshop participants which of them are fulfilled. Depending on the portion of the criteria that has been fulfilled, he or she articulates the result: "yes," "no," or "investigation required."

Reporting. After the workshop, the team prepares a written report containing the result, the rationale, and a recommendation.

The rationale maps the personnel's core responses to the product line potential definition; for example, the information provided on the number of products plus the amount and cost of their software is used to justify the assertion that there is a set of software-intensive systems.

Typical recommendations are

- to perform a Product Line Technical Probe ${ }^{\mathrm{SM}}\left(\mathrm{PLTP}^{\mathrm{SM}}\right) \sqrt{1}$

- to do an Architecture Tradeoff Analysis Method (ATAM ${ }^{\mathrm{SM}}$ ) evaluation

- to perform a Scoping workshop

The PLTP $^{\mathrm{Sm}}$ as described by Clements and Northrop [2] is a method for examining an organization's readiness to adopt the PLA. A PLTP ${ }^{\mathrm{Sm}}$ can be recommended if the Product Line Potential Analysis result is "yes."

An ATAM $^{\text {SM }}$ 3] examines the risks contained in a particular software architecture. An $\mathrm{ATAM}^{\mathrm{SM}}$ can be recommended if the Product Line Potential Analysis reveals that a software architecture already exists and should be used for product line development.

Scoping defines which products should be part of a product line or which product lines a business unit should develop. A Scoping workshop can be recommended if the Product Line Potential Analysis reveals that it is not clear which products are to be developed in the product line.

\section{Discussion}

\subsection{Example}

So far, our team has performed four Product Line Potential Analyses, the results being four "yes" decisions plus one "investigation required." Before we started performing Product Line Potential Analyses, we had expected to exit each workshop with a single result. But in one Product Line Potential Analysis, we experienced something different.

\footnotetext{
${ }^{1}$ PLTP, Product Line Technical Probe, ATAM, and Architecture Tradeoff Analysis Method are service marks of Carnegie Mellon University.
} 
A business unit had asked for a Product Line Potential Analysis for its new generation of systems. The unit planned to manufacture two kinds of large systems: A and B. From type A, about 40 small, specific systems should be derived, $\mathrm{A}_{1}-\mathrm{A}_{40}$.

The result of the analysis was twofold:

1. The PLA makes sense for a product line including systems $A$ and $A_{1}-A_{40}$.

2. Investigation is required to decide whether $\mathrm{B}$ belongs to this product line, too.

Systems A and B are just two products, even though they are highly configurable systems. To decide whether the PLA makes sense anyway, we would need a closer look. Therefore, we recommended a Scoping workshop.

\subsection{Related Work}

If a business unit is considering launching a product line, some analysis methods would provide a good start, notably

(a) Domain Potential Analysis ([1])

(b) Product Line Analysis ([5])

(c) Product Line Benefit and Risk Assessment ([6])

(d) PuLSE ${ }^{\mathrm{TM}}$-Intro ([4])

(e) Product Line Technical Probe ${ }^{\mathrm{SM}}([2])$

The fundamental difference between these methods and the Product Line Potential Analysis is the effort involved. The Product Line Potential Analysis is designed to take a quick look. It doesn't analyzes reuse benefits and risks (as (a) - (d) do) or assess expertise (e).

These activities require thorough analysis and are therefore time-consuming - for the consultants as well as for the clients. Experience shows that business units are not willing to spend time and resources on extensive analysis before they know that a product line approach fits their product palette. Product Line Potential Analysis gives them confidence within a few hours.

The above mentioned method (c) is an assessment, (d) is called a probe. A Product Line Potential Analysis is neither. It is a survey done in partnership. Both sides give and take information. In particular, the result emerges during the workshop as opposed to assessments where the team works out the result on its own after the interviews.

\subsection{Limits}

The guaranteed result of the Product Line Potential Analysis is a "yes," "no," or "investigation required" decision. In our Product Line Potential Analysis presentation, we explain carefully to the business unit personnel that this and nothing more can be expected. The time is needed to understand the products, markets, 
and some essential properties of the software. There is no time to analyze possible product lines, domains, or architectures. However, after each workshop we've done so far, we were able to give one or two recommendations. But we cannot promise to give one; it is an add-on.

Product Line Potential Analyses bear the risk of missing possible product lines, because the scope of a Product Line Potential Analysis corresponds to the scope our interviewees have. Organizations and products reflect traditional divisions. In a Product Line Potential Analysis, we talk to personnel of one business unit. Thus, we can see product line potential inside one division. We can't see a possible product line that would include products of two divisions. A Product Line Potential Analysis has to comply with these limitations.

The Product Line Potential Analysis was designed in the context of Bosch, including automotive products and building products. We think that the method would transfer to other organizations, because it analyzes the products, not their development. If limitations in transfer exist, they probably lie on the market and customer side. So far, we have analyzed known markets and products: the contracting customers of automotive products are the car manufacturers. Perhaps some questions would need to be changed or added if the markets or customers were not that well known.

\section{Conclusions}

\subsection{Summary}

A Product Line Potential Analysis decides in a half-day workshop whether the PLA is suitable for a given set of products and their market using a structured interview based on a questionnaire. The result is basically "yes," "no," or "investigation required." We have presented

- the criteria relevant to PLA applicability

- a part of our questionnaire

- how Product Line Potential Analysis workshops are executed

- a discussion of the method

\subsection{Lessons Learned}

- Each criterion is relevant. It is important to play it safe. Even if some of them may seem trivial; for example, the requirement that there be more than one product: A product unit showed interest in applying the PLA. They fulfilled all main and inclusion criteria, except one. They sold different products, but they developed only one - a configurable software.

- We have learned to conduct the interview in such a way that business unit employees feel good. They want to understand the purpose of our questions. We explain it. We explain immediately how their answers relate to the PLA, too. This gives them confidence and motivation. 
- We regard a Product Line Technical Probe ${ }^{\mathrm{SM}}$ as the most effective and efficient initiation of a PLA. However, executives hesitate to order it. A PLTP ${ }^{\mathrm{Sm}}$ is an investment that ties up resources of about two person-months. Holding a positive Product Line Potential Analysis result in the hand reduces the inhibition threshold: the executive knows that the effort of performing a $\mathrm{PLTP}^{\mathrm{SM}}$ is well invested. On the flip side, the information we get during the Product Line Potential Analysis shortens the preparation of a PLTP ${ }^{\mathrm{SM}}$.

- Performing a Product Line Potential Analysis is a very effective and efficient way to understand the business, the products, and the market of a business unit. And we make contact with the executive manager of a business unit or product unit. This provides valuable information for a Scoping workshop and helps to find the right stakeholders.

\subsection{Future Work}

So far, only PLA experts can lead a Product Line Potential Analysis, because our criteria are soft. When we ask "How big is your software?" (LOC, RAM/ROM usage, or number of developers), we do not know how big would be just big enough. In case we run into a conflict, we either recommend further investigation or recognize that this factor will not change the result. Doubtlessly, we would prefer to have hard data to decide such issues.

Having this hard data would make our questionnaire much more precise. We could refine it so that a Product Line Potential Analysis could be led by other corporate units or maybe by the business units themselves.

\section{References}

1. S. Bandinelli, G. Sagardui Mendieta Domain Potential Analysis: Calling the Attention on Business Issues of Product-Lines in Proceedings of Software Architectures for Product Families, International Workshop IW-SAPF-3, Las Palmas de Gran Canaria, Spain, March 15-17 2000, Lecture Notes in Computer Science 1951 Springer 2000, ISBN 3-540-41480-0

2. P. Clements, L. Northrop Software Product Lines, Addison-Wesley 2002

3. P. Clements, R. Kazman, M. Klein Evaluating Software Architectures, AddisonWesley 2002

4. Fraunhofer Institute for Experimental Software Engineering (IESE) PuLSE ${ }^{T M}$ Intro - Identifying the potential for effective development of software product variants, www.iese.fgh.de

5. G. Sagarduy, S. Bandinelli, R. Lerchundi Product-line Analysis: Do we go ahead? in Proceedings of Software Product Lines: Economics, Architectures, and Implications, Workshop \#15 at 22nd International Conference on Software Engineering (ICSE), Limerick, Ireland, June 10th 2000

6. K. Schmid, I. John Developing, Validating and Evolving an Approach to Product Line Benefit and Risk Assessment, in Proceedings of 28th Euromicro Conference (EUROMICRO'02), September 04-06, 2002, Dortmund, Germany, IEEE 2002 